\title{
Study of Radical Polymerizations by Spin Trapping. I. Trapping of Initiating and Propagating Radicals
}

\author{
Toyoki Kunitake and Sigeru Murakami \\ Department of Organic Synthesis, Faculty of Engineering, \\ Kyushu University, Fukuoka, Japan. \\ (Received July 31, 1971)

\begin{abstract}
KEY WORDS Spin Trapping / Radical Polymerization / Initiating
Radical / Propagating Radical /
\end{abstract}

The spin trapping technique has been receiving increasing attention in the study of free radical chemistry ${ }^{1}$. An application of this technique to the free radical polymerization of styrene was recently reported by Chalfont, et al. ${ }^{2}$

It is expected that the course of free radical polymerization can be further clarified by trapping the various radicals involved. In this paper we describe trapping of initiating and propagating radicals and the isolation of trapped polymer radicals.

2-Methyl-2-nitrosopropane ( $t$-BuNO, mp 70$73^{\circ} \mathrm{C}$ ) was prepared according to Emmons ${ }^{3}$, and used as the trapping agent. As noted already, this reagent has an advantage in that the structure of radicals being trapped can be inferred from the hyperfine splitting of the ESR spectrum of the stable nitroxide radical formed.

The polymerization of styrene was carried out at $70^{\circ} \mathrm{C}$ with $\mathrm{AIBN}$ initiator in the presence of $t$-BuNO. An ESR spectrum of this polymerization system can be interpreted as the overlapping of a three-line spectrum of the trapped initiating radical $\mathbf{I}$ and a six-line spectrum of the trapped styryl radical II.<smiles>CC(C)(C)N([O-])C(C)(C)C#N</smiles>

I<smiles>CCC(CC)N([O-])C(CC)c1ccccc1</smiles>

II
It is interesting to note that the spectral intensity of I relative to II increased with increasing concentration of $t$-BuNO in the polymerization system. Accordingly, measurements were taken of polystyrene which was separated by reprecipitation from this reaction mixture. Only a sixline spectrum of the trapped polystyryl radical

Table I. Hyperfine splitting constant of trapped polymer radicals ${ }^{a}$

\begin{tabular}{lccc}
\hline \multirow{2}{*}{$\begin{array}{c}\text { Monomer } \\
\text { (or initiator) }\end{array}$} & $\begin{array}{c}\text { Method of } \\
\text { measurement }^{\mathrm{b}}\end{array}$ & \multicolumn{2}{c}{ Hyperfine splitting } \\
\cline { 3 - 4 } & $\mathrm{A}$ & 15.5 & $a_{\mathrm{N}}, \mathrm{G}$ \\
AIBN & $\mathrm{B}$ & $14.9(14.5)^{\mathrm{c}}$ & - \\
Styrene & $\mathrm{B}$ & 13.9 & $2.15(3.3)^{\mathrm{c}}$ \\
Methyl acrylate & $\mathrm{A}$ & 14.9 & 2.77 \\
Acrylonitrile & $\mathrm{A}$ & 12.6 & 1.81 \\
Vinyl acetate & $\mathrm{B}$ & 15.1 & - \\
Methyl methacrylate & &
\end{tabular}

a Polymerization condition: $70^{\circ} \mathrm{C}$; solvent, benzene; monomer, $4 \mathrm{~mol} / l$; initiator, AIBN or BPO, 0.04 $\mathrm{mol} / l ; t$-BuNO, $2 \times 10^{-2}-4 \times 10^{-3} \mathrm{~mol} / l$.

b A, determined from the ESR spectrum of the polymerization mixture; B, determined for the separated polymer in benzene.

c $c f$. ref. 2. Estimated from the ESR spectrum of a polymerization mixture without isolating polymer. 
II was observed.

Similar experiments were conducted for other vinyl monomers, and the hyperfine splitting constant of trapped polymer radicals is given in Table I. The splitting constant varies characteristically with the structure of the trapped radical. Thus, the ESR spectroscopic investigation of the polymer obtained in the presence of $t$-BuNO is a particularly effective method of dissecting the structure of propagating radicals. Application of this method in a living anionic polymerization system was recently reported by Forrester and Hepburn ${ }^{4}$.

Figure 1a is an ESR spectrum of a polymerization mixture (AIBN-methyl methacrylate$t$-BuNO system). This is principally a three-line spectrum which is formed by exact overlapping of spectra of the trapped initiating and polymer radicals. A complex multiplet of smaller intensity is present in addition to this three-line spectrum. In Figure 1b is shown a spectrum

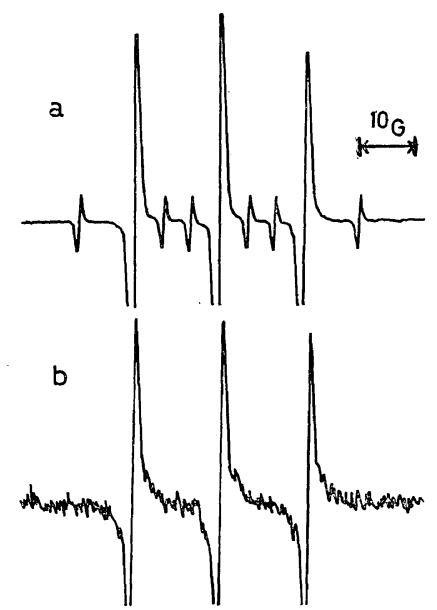

Figure 1. ESR spectra of trapped radicals: (a) ESR spectrum of polymerization mixture. $g=$ 2.0068. Polymerization condition: monomer, methyl methacrylate $4 \mathrm{~mol} / l$; solvent, benzene; initiator, AIBN $1 \mathrm{~mol} \%$ of monomer; $t$-BuNO, $0.5 \mathrm{~mol} \%$ of monomer; polymerization temp., $60^{\circ} \mathrm{C}$; polymerization time, $30 \mathrm{~min}$. (b) ESR spectrum of trapped poly(methyl methacrylate) radical dissolved in benzene. $g=2.0067$. Polymerization condition; monomer, methyl methacrylate $4 \mathrm{~mol} / l$; solvent, benzene; initiator, AIBN 1 mol\% of monomer; polimerization temp., $70^{\circ} \mathrm{C}$. The polymer was reprecipitated three times from benzene and methanol. of the trapped polymer which was purified by reprecipitation. A clean triplet $\left(a_{N}=15.1 \mathrm{G}\right)$ of diminished intensity is observed, consistent with the structure of the propagating radical. Therefore, the multiplet in Figure 1a is not ascribable to the trapped polymer radical. Similar multiplets were detected in the polymerization of other $\alpha$-methyl-substituted monomers: methacrylic acid, methacrylonitrile, $\alpha$-methylstyrene. In addition, when a mixture of methyl methacrylate and $t$-BuNO in benzene was maintained at $70^{\circ} \mathrm{C}$, there was observed a clean nine-line spectrum which is a triplet (intensity, $1: 2: 1$; splitting constant, 10.1G) of a nitrogen triplet (identical intensity, $\left.a_{\mathrm{N}}=15.2 \mathrm{G}\right){ }^{*}$ Thus thenineline spectrum observed for $\alpha$-methyl-substituted monomers is probably due to abstraction of the allylic hydrogen by thermally formed $t$-butyl radical. Thermolysis of $t$-BuNO is well known $^{6}$ :

$t$-BuNO $\rightarrow t$-Bu$\cdot+\mathrm{NO}$

$t-\mathrm{Bu} \cdot+\underset{\mathrm{CH}_{2}=}{\stackrel{\mathrm{C}}{\mathrm{C}}} \underset{\mid}{\mid} \rightarrow \mathrm{CH}_{2}=\underset{\mathrm{C}}{\mathrm{C}}+t-\mathrm{BuH}$<smiles>[X]C(=C)CN(O)CC([X])=CONCCCC</smiles>

The initiating radicals used (PhCOO., $\left.\left(\mathrm{CH}_{3}\right)_{2}-\mathrm{C} \cdot\right)$ appear to be incapable of hydrogen $\mathrm{CN}$

abstraction.

In conclusion, it was shown that spin trapping with $t$-BuNO as trapping agent was effective in the structure elucidation of the propagating radical and that spin-labeled polymers are readily prepared. On the other hand, it is necessary to discriminate the radical process which is brought about by side-reactions of trapping agents.

Acknowledgement. The authors extend deep appreciation to Dr. Chuji Aso, former head of our research group, for his encouragement and advice. They are also very grateful to Prof. Y.

* An $a_{\mathrm{H}^{\beta}}$ value of this magnitude has been found for several radicals trapped by $t$-BuNO: $11.3 \mathrm{G}\left(\mathrm{CH}_{3} \cdot\right)$, $10.4 \mathrm{G}\left(\mathrm{CH}_{3} \mathrm{CH}_{2} \cdot\right)$ and $7.25 \mathrm{G}\left(\mathrm{B}_{6} \mathrm{H}_{5} \mathrm{CH}_{2} \cdot\right)^{5}$. 
Spin Trapping Study of Radical Polymerization

Murakami and Dr. Y. Matsuda of this Department for use of ESR equipment (Jeolco, JM-ME 3 ) and for their stimulating discussions.

\section{REFERENCES}

1. For a recent survey see E. G. Janzen, Accounts Chem. Res., 4, 31 (1971).
2. G. R. Chalfont, M. J. Perkins, and A. Horsfield, J. Amer. Chem. Soc., 90, 7141 (1968).

3. W. D. Emmons, ibid., 79, 6522 (1957).

4. A. R. Forrester and S. P. Hepburn, J. Chem. Soc., Sect. C 1971, 701.

5. M. J. Perkins, P. Ward, and A. Horsfield, ibid., Sect. B, 1970, 395.

6. B. G. Gowenlock and M. J. Healey, ibid., Sect. B, 1968, 1014. 